\title{
Research on the Style System of Diversified Choreography in Line Dance
}

\author{
Hongfang Li
}

Taishan University, Taian, Shandong, 271000

Keywords: Line dance; diversification; the plait style

\begin{abstract}
At present, due to the lack of a unique understanding of choreography creation style by dance professionals, few choreography created by our own people have been found in the world dance choreography. Therefore, it is necessary to innovate line dance style of the plait, such as adding national dance element in the line dancing, which can make line dancing creating style diversified, and the line dance movement can play an important role.
\end{abstract}

\section{Line Dance}

Row dancing originated in the 1970s, when cowboy dance was very popular in the western American countryside. Local people often dance to the guitar by clapping their hands to celebrate various activities. The English name of platoon Dance is "Line Dance", which translates to Line Dance. Later, after a long period of development, the style of platoon Dance gradually diversified, and Latin platoon Dance and European court platoon Dance were introduced. Platoon dance can be performed alone or in groups. It is a new type of dance with different styles. Usually, line dance accompaniment for a complete song, the dance elements has certain international, creating and distinctive style, fashion, not affected by the number, sites, weather and other uncontrolled factors, the most important thing is to improve human cardiopulmonary function and body coordination, therefore, following the introduction of our country since 2004, line dance more and more get the pursuit and love of men and women, old and young.

\section{The Application of Folk Dance Elements in the System of Diversified Choreography Style}

\subsection{Tibetan dance elements in the diversity of choreography in the creative style}

Tibetan dance with unique national flavor, tend to merge in the dance interpretation of farming culture and religious culture, when the music sounded, people will borrow lyrical dance, the posture of graceful dance and charming formed unique dance art form in the Tibetan laboring people. Tibetan dance has the unique characteristics of "one side follows the other" of hands and feet, and it also has the basic features of looseness, bow waist and back bending. Tibetan dance elements are introduced in the creation and compilation of row dance, whose music style is continuous, relaxed and lively, and forms the upper and lower limbs movement of changing multiple ends and flowing water in the dance step. Tibetan style line dance "zha-xi-de-le", for example, in which the introduction of "GuoZhuang" unique dance to welcome people, blessing propitious, the same line dancing, condensed the Tibetan pace at the same time, leading the era characteristic. The public can also experience the national charm through the introduction of Tibetan dance movements, as well as strengthen their physical fitness, which is strongly welcomed by the masses of the people.

\subsection{The creation style of dong dance elements in the diversity of choreography}

Dong people almost all people will sing, here also is known as a "sea" of poetry, they often sang and danced, more than in the local ethnic customs such as "duo", lusheng dance folk dance. In dance, men and women are often divided into two teams, into two circle, hand in hand with music dancing in circles, his hands back and forth at the same time, the heels around the body movement, dance very warm atmosphere, has become an indispensable part of the local people's life. In the international line dance with dong dance elements of "more karma and get the attention of people, it belongs to the original song and dance, very strong local characteristics, lusheng dance elements 
and line dancing, the combination of the dong people's unique shape and dance, the dong people are hospitable and honest good side can better show.

\subsection{Mongolian dance elements in the diversity of choreography in the creative style}

Mongolian ancient working people living in the steppe, long nomadic life make their enthusiasm and bold personality, they are in the process of dance, women often use shake shoulders, soft hand, deliberate steps to express their joy, men often use the pace of the free and easy and forceful dance to express their own brave and strong. The Mongolian people showed their bravery and bravery in waving, whipping and jumping, and their national characteristics were very distinctive. Mongolian dance breathing coordination and uniformity to the body the demand is higher, line dance style and a comparison in Mongolia, founder of the famous Dunbar root, he would line dance style and the combination of Mongolian dance style, creating a lot with rich Mongolian characteristic line dancing, such as "the festival", "urga" and so on. In line dance interpretation will also be transverse twist, imitating horse riding, ground shaking, shoulder, classic action is blended in among them, the action is easy to learn, rhythm is very clear, dance accompanied by music when driving the enthusiasm of people, line dance introduced in Mongolian dance has a lasting appeal.

\subsection{The creation style of Qiang dance elements in the diversity of row dance}

Since ancient times, qiang working people have been living in the plateau environment, because the environment is very bad, in order to protect themselves and gradually form a good character, mainly leg movements in the process of the dance, both arm action. Qiang people often give voice to their feelings by Shouting and stepping on the ground instead of music in the dance performance, and release themselves to the fullest in the dance. There is no very standard or standard action requirement. In general, the local people divide the qiang dance into two styles, namely, "ballon" and "witch dance". Qiang dance has the edge on the same line, in the lean and physical characteristics of "S" type, is in the middle of the line dance "the qiang mountain, just to use this feature, the dance is through the folk song singing in the form of a line dance, song qiang lasting appeal is very strong, also show the qiang people's enthusiasm, kindness and the pursuit of a better life. In line dance hand in hand, will a variety of qiang dances for effective integration, such as "green trees suck up wine", "Sharon dance", "kai a dance", "heishui", etc., the plait style is unique.

\subsection{The creation style of miao dance elements in the diversity of choreography}

The miao nationality has many branches of dance, rich history and culture, and many varieties. In the history of dance development, lusheng dance, wooden dance, bronze dance and xiangxi dance are the main ones. For example, lusheng dance pays attention to the flexibility of lower limbs and mainly takes the four-step dancing method. In addition, it also has the right and left rotation, rubbing step, jumping step and point step. In ancient times, the miao people lived by hunting and agricultural production, and they needed to use various movements such as "catching shrimp" and "fishing". These classic movements were used in the bronze dance. MuGuWu is simulated "hunting", "the bull", "cattle" in the classical action, use the wooden drum beat playing, and the Mercedes bouncing gait to participate in, to form the characteristics of different styles of dance. More famous line dance of miao have "lang in mountain looked at", etc., used in the dance of MuGuWu waist left hip, lusheng dance of short step jump method and so on, through the line dance real expression of the miao people's sincere feelings and desire for a better life.

\section{The Requirement of Integrating Ethnic Dance Elements into the Diversified Creation Style System of Line Dance}

In the development of The Times today, the style system of choreography is no longer single, but towards a diversified way of development. In the process of creation and compilation, a single movement needs to be integrated. According to the characteristics and rules of the choreography, countless movements are connected together to form a beautiful dance posture and a complete dance paragraph. Our country has many minorities, formed in the long folk dance in a wide range of 
elements, this would require the creator and in the process of line dance the plait, skills and knowledge for line dance master, the thought of dance and music of all ethnic groups emotion, trying to make national dance elements and basic principles of line dance the plait to adapt to each other, at the same time, also put forward higher request for music and dance.

In the creation and compilation of row dance, the effective integration of the complete music is required. Only in this way can row dance have a strong appeal. Because our country because of the national culture, the different geographical environment and folk customs, in the national music deduce also presents different characteristics, creator and to the national music mutual integration, you need to deepen the understanding of national music, but also according to dancing to the music carefully, through the elaborate design of music, make line dance with the emotional expression is more fresh and strong artistic rendering.

Line dance the plait need complete dance moves, which requires more than a single action to complete, so the time control of the dance moves in line dancing, rhythm control, power control and trajectory control is very important. The choreography of platoon dance should follow its own dance rules when it is created. From music to action, it needs to keep people's emotions in order to choose dance movements and music style. For integrated into the national dance elements, need according to the working people of religious culture and lifestyle differences to the plait of line dance, such as diversification of the plait style makes the line dance diversity and makes people have more demand in line dance interpretation and choice, when the music melody rang out gradually, people can choose by music, dancing, and diverse style of the plait.

\section{Conclusion}

Has a long history in China, 56 ethnic groups have belong to own national dance elements, in the line dance the plait into the fresh blood, enhance innovation of line dance movements, make line dance more tenacious vitality, creating more diverse style system.

\section{References}

[1] Fengying Deng. On the promotion of ethnic Tibetan qiang guanzhuang's volleyball and dance [J]. Chinese and foreign entrepreneurs, 2017, (2):270.

[2] Zun Li. Analysis of the elements and characteristics of choreography [J]. Journal of chengdu sports university, 2012,38(10):55-58.

[3] Yan Zhang. Research on the creation and compilation of Chinese folk dance elements [J]. Hunan normal university, 2016,78(2):185-191.

[4] Qian Bao. Strategies and methods of choreography [J]. Sichuan sports science, 2010 (4):123-127.

[5] Yanhong Zhou. The inheritance and innovation of qiang culture -- an empirical study on the creation method of qiang dance [J]. Movement, 2013 (21):149-150.

About the author:

Hongfang Li, female, born on July 25, 1978, native place: feicheng, shandong province, education background: master degree, title: lecturer, research direction: aerobics teaching and training 